\title{
The use of hyoid bone dimensions in age and sex estimation in a Turkish population: a cone-beam computed tomography study
}

\author{
E. Köse ${ }^{1}$, D. Göller Bulut ${ }^{2}$ \\ ${ }^{1}$ Department of Oral and Maxillofacial Radiology, Faculty of Dentistry, Aydın Adnan Menderes University, Aydın, Turkey \\ ${ }^{2}$ Department of Oral and Maxillofacial Radiology, Faculty of Dentistry, Bolu Abant izzet Baysal University, Bolu, Turkey
}

[Received: 22 April 2021; Accepted: 1 May 2021; Early publication date: 17 May 2021]

\begin{abstract}
Background: The aim of the study was to determine sex and age from hyoid bone morphology on cone-beam computed tomography (CBCT).

Materials and methods: The study sample comprised 130 CBCT images. Eight different measurements were performed for each hyoid bone. Fusion conditions were assigned to each side of the hyoid bone separately as; unfused, partially fused, and totally fused.

Results: The hyoid length, width of the left proximal end and stature variables showed sexual dimorphism in all hyoid fusion types $(p<0.05)$. In young adult age group, a significant difference was found between sex and fusion types $(p=0.025)$. The body length (81.35\%) and stature measurements $(76.25 \%)$ contributed most significantly to sex estimation.

Conclusions: Patient's CBCT scans which enable reproducible and reliable measurements for bone tissues can be used for forensic procedures. Hyoid bone measurements with CBCT are useful methodology for age and sex estimation in forensic sciences with high predictive accuracy. (Folia Morphol 2022; 81, 1: 183-189)
\end{abstract}

Key words: age estimation, hyoid bone fusion, hyoid bone measurement, sex estimation

\section{INTRODUCTION}

Sex identification is an important forensic and archaeological procedure $[1,20]$. Comparison of ante mortem and post mortem records and examination of bones have a crucial role for identification $[20,21]$. Pelvis, skull and long bone measurements are usually used for sex estimation [20]. But these bones may be damaged - burned and fragmented - because of disasters. In such cases, determined sex is usually used as an estimation of other biological features like age and ancestry. Thus, another method using other bones should be established for cases where the pelvis, skull and long bones are unavailable [21].

The hyoid bone originates from the branchial arches and arch cartilages [7]. It is a solitary bone without any bony articulations [5, 9]. It has muscles, ligaments and fascia attachments from cranium, mandible and pharynx that provide physiological functions; including speaking, breathing, swallowing and keeping the upper airway open during sleep $[6,7,11,15]$. The hyoid bone has distinct morphological features that allow forensic researchers to quickly

Address for correspondence: Assist. Prof. E. Köse, Department of Oral and Maxillofacial Radiology, Faculty of Dentistry, Adnan Menderes University, Aydın, Turkey, tel: +90-256-213 3939/3345, e-mail: mail_emrekose@hotmail.com

This article is available in open access under Creative Common Attribution-Non-Commercial-No Derivatives 4.0 International (CC BY-NC-ND 4.0) license, allowing to download articles and share them with others as long as they credit the authors and the publisher, but without permission to change them in any way or use them commercially. 
identify it. U-shaped bone lies anteriorly to fourth cervical vertebra in adults and is composed of a body, two greater cornua and two lesser cornua $[5,7,15]$. These cornua which are directed postero-laterally are attached to the body by synchondrosis [15]. Some hyoid bones show a diarthrodial structure and have a gap between body/cornua bone articulation [10].

Measurements of hyoid bone and the degree of fusion between hyoid bone and greater cornua might be helpful in age and sex estimation. Several studies including cadavers, photographs, and radiographs have used hyoid bone for sex estimation $[1,7,11,15]$. Among these techniques, radiological assessment is important for age calculation and sex estimation. It is simple, easily applicable and non-invasive method, and can be evaluated in living individuals as well as in the dead. Cone-beam computed tomography (CBCT) is a radiological imaging system that provides three-dimensional visualisation of the anatomical structures and gives realistic measurements. While there are studies evaluating hyoid bone for age and sex estimation, no study has been found that examine sexual dimorphism of hyoid bone measurements of living patients in a contemporary Turkish population with CBCT images.

The aim of this study was to evaluate the fusion between hyoid body and cornua, and hyoid bone measurements in sex estimation and aging using CBCT images.

\section{MATERIALS AND METHODS}

In this retrospective study, $C B C T$ images, which were performed because of patients' dental problems, from database of oral and maxillofacial radiology department of Aydın Adnan Menderes University were used. The study was approved by the local ethical committee (No: 2020/36). For this study, 650 CBCT scans from lower jaw that were performed between October 2014 and February 2019 were visually inspected. Fractures and acquired or congenital abnormalities of hyoid bone were excluded from study. Images with whole hyoid bone structure visible and without any artefacts were included. According to inclusion and exclusion criteria, a total of 130 CBCT scans were selected for the study. The CBCT scans were obtained using standard exposure parameters and patient positioning protocols (field of view: $20 \times 10 \mathrm{~cm}$ and $20 \times 15 \mathrm{~cm}$, resolution: $0.2-0.4 \mathrm{~mm}$, 80-84 kVp, 8-12 mA) with a CBCT unit (Planmeca promax 3D Max, Helsinki, Finland). Romexis version 4.6.2. software (Planmeca, Helsinki, Finland) was used for hyoid bone measurements. Inter- and intra-observer rates were calculated by re-evaluating 30 randomly selected subset data (15 males and 15 females). The original author examined and measured all scans and the subset data. Co-author examined and measured the subset data to assess interobserver error. Coefficient of reliability $(R)$ and relative technical error of measurements (rTEM, \%) were calculated. $R$ value $>0.75$ was considered sufficiently exact which reveals the quantity of the between-subject variance free of measurement errors [25]. The acceptance ranges of rTEM for intraobserver errors and interobserver errors were $<1.5 \%$ and $<2.0 \%$, respectively [24].

Axial, sagittal, coronal and oblique views were investigated. All of the measurements were made from axial images that were obtained and corrected with slice-by-slice tracing of coronal and sagittal images. Eight measurements were performed for each hyoid bone as below:

- Hyoid width (Hyd-W) - linear distance between the most distal points of the greater cornua of the hyoid (Fig. 1A);

- Body length (B-L) - linear distance between the right and left most lateral surfaces of the hyoid body (Fig. 1A);

- Hyoid length (Hyd-L) - perpendicular length from the most anterior surface of the hyoid body to the line that links the most lateral points of the greater cornua of the hyoid body (Fig. 1B);

- Width of the left proximal end (LP-W) and right proximal end (RP-W) maximum width of the proximal end of the left and right greater cornua (Fig. 1C);

- Diameter of the left distal end (LD-D) and right distal end (RD-D) maximum diameter of the distal end of the left and right greater cornua (Fig. 1C);

- Hyoid bone length sum of distances (stature): bilateral linear distance between the most distal point of greater cornua and middle point of proximal surface of greater cornua, and bilateral linear distance between middle point of distal surface of hyoid body and the most proximal point of hyoid bone (Fig. 1D). Fusion conditions were assigned to each side of the hyoid bone separately. The smallest distance between the greater cornua and hyoid body on each side was assessed and following three grades defined as below:

- Unfused - there is a space between the nearest points of the hyoid body and greater cornua without any contact (Fig. 2A);

- Partially fused - there is a line with lower intensity between partially fused body and greater cornua. Fusion is not uniform (Fig. 2B); 

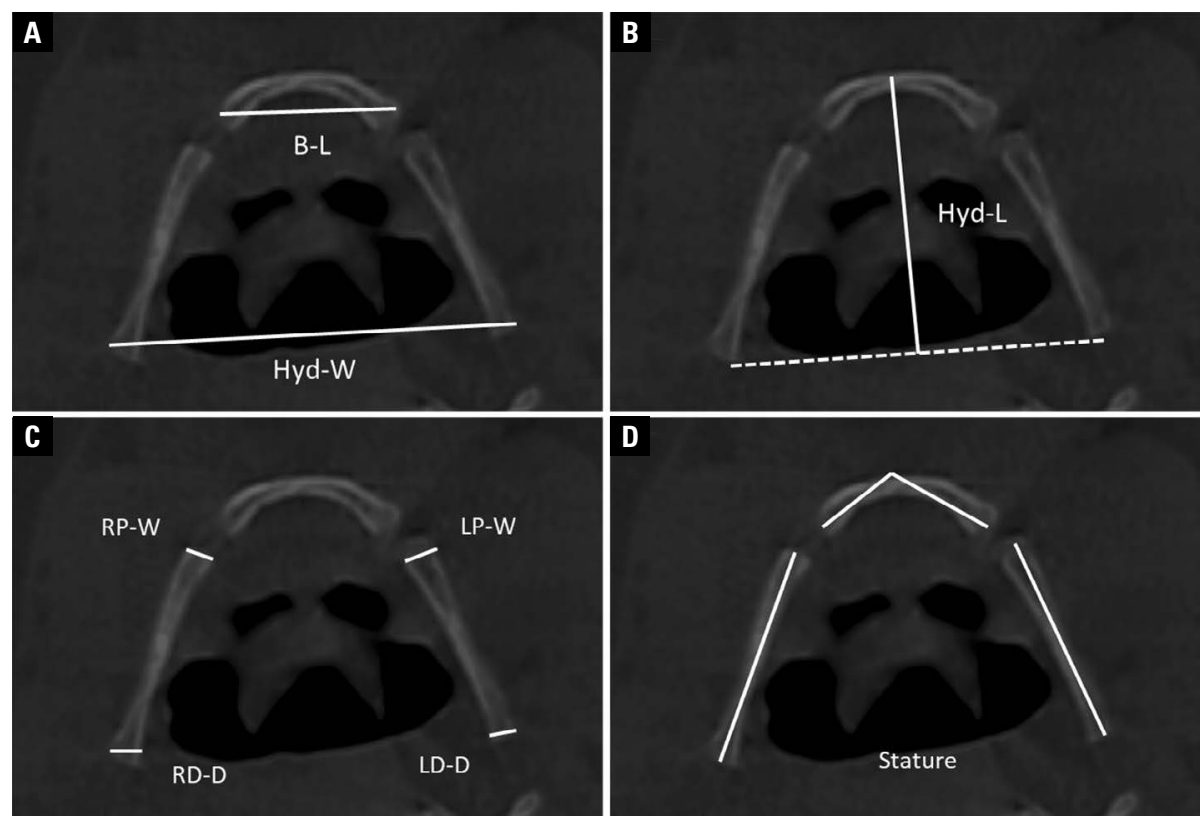

Figure 1. Measurements of hyoid bone; A. B-L — body length; Hyd-W — hyoid width; B. Hyd-L — hyoid length; C. RP-W — width of the right proximal end; RD-D — diameter of the right distal end; LP-W — width of the left proximal end; LD-D — diameter of the left distal end; D. Stature: total length of hyoid.
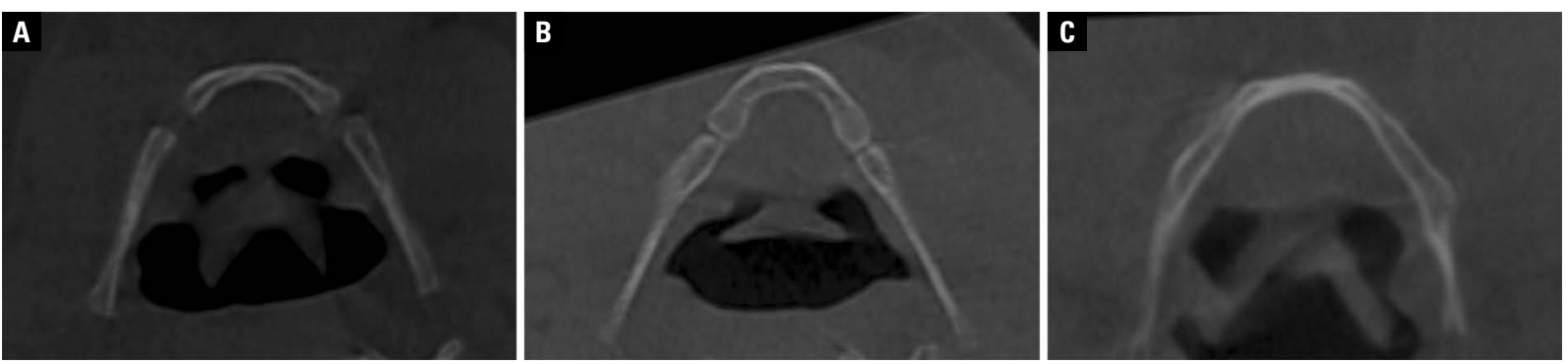

Figure 2. Fusion conditions of hyoid; A. Unfused; B. Partial fused; C. Totally fused.

- Totally fused - there is a uniform fusion without any space between the hyoid body and greater cornua. A line of fusion may be visible or invisible as one continuous structure (Fig. 2C).

\section{Statistical analysis}

Statistical analyses were done on a personal computer using SPSS (IBM Statistical Package for the Social Sciences Statistics; New York, ABD) version 21.0 computer software. Means, standard deviations, and ranges of all hyoid bone measurements were calculated according to age. The normality was assessed using the Shapiro-Wilk test. The mean differences between the sexes in the all hyoid measurement data were assessed using two-sample independent t-test. The association of fusion types with sex and age groups were analysed with $\chi^{2}$ test and Pearson correlation. Statistically significant level was considered at a $p$ value of $<0.05$.

Univariate discriminant function analysis for sex classification was used for all measurements. Then stepwise discriminant function analysis was used to find most accurate sex classification. Function at group centroids were calculated, sectioning points for each measurements were calculated by adding group centroids and dividing their total by 2 . Wilk's lambda was calculated. Correct prediction rates were calculated by the leave-one-out cross validation test.

\section{RESULTS}

Table 1 demonstrates the $R$ and rTEMs values. The $R$ values ranged from 0.96 to 0.99 . The rTEMs values for interobserver and intraobserver errors ranged 
Table 1. The coefficient of reliability $(\mathrm{R})$ and the relative technical error of measurement (rTEM) $(n=30)$

\begin{tabular}{lccccc}
\hline \multirow{2}{*}{ Variable } & \multicolumn{2}{c}{ Intraobserver } & & \multicolumn{2}{c}{ Interobserver } \\
\cline { 2 - 3 } \cline { 5 - 6 } & $\mathbf{R}$ & rTEM & & $\mathbf{R}$ & rTEM \\
\hline Hyd-W & 0.96 & $1.54 \%$ & & 0.96 & $1.24 \%$ \\
B-L & 0.98 & $1.32 \%$ & & 0.96 & $1.85 \%$ \\
Hyd-L & 0.99 & $1.45 \%$ & & 0.97 & $1.63 \%$ \\
RD-D & 0.99 & $1.03 \%$ & & 0.98 & $1.25 \%$ \\
RP-W & 0.98 & $0.88 \%$ & & 0.97 & $1.12 \%$ \\
LD-D & 0.99 & $1.35 \%$ & & 0.99 & $1.54 \%$ \\
LP-W & 0.98 & $1.66 \%$ & & 0.96 & $1.36 \%$ \\
Stature & 0.96 & $1.08 \%$ & & 0.96 & $1.94 \%$
\end{tabular}

Hyd-W — hyoid width; B-L — body length; Hyd-L — hyoid length; RD-D — diameter of the right distal end; RP-W - width of the right proximal end; LD-D — diameter of the left distal end; LP-W — width of the left proximal end

from $1.03 \%$ to $1.88 \%$ and from $1.12 \%$ to $1.94 \%$, respectively. The mean, standard deviation, and ranges of all hyoid bone measurements according to gender were shown in Table 2. There were significant differences between sexes for all measurements except the LD-D ( $p=0.437)$. There is no significant difference in the mean age of genders $(p=0.123)$. No significant difference was found between RD-D and LD-D, RP-W and LP-W ( $p=0.448$ and $p=0.700$, respectively).

The measurement means and standard deviations according to fusion types for males and females in the population are shown in Table 3. The mean age of subjects in all hyoid fusion types showed no difference with regard to sex. Outcomes of the two-sample independent t-test for sexual differences between genders are shown in Table 4. The Hyd-L, LP-W and stature variables showed sexual dimorphism in all hyoid fusion types.
Types of fusion according to sex and age groups are presented in Table 5. In young adult age group, a significant difference was found between sex and fusion types ( $p=0.025$ ), although there were no significant difference in adults and $<20$ years groups ( $p=0.068$ and $p=0.150$, respectively). The results of univariate discriminant function analyses for the hyoid bone measurements are shown in Table 6 . The B-L (81.35\%) and stature measurements (76.25\%) contributed most significantly to sex estimation.

\section{DISCUSSION}

In forensic science, it is important that measurements made on any structure be reproducible and reliable. Additionally, measurements should be identified and explained clearly to understand definition [14]. Several studies have used hyoid bone measurements for sex and age estimation. Most of these studies included direct bone measurements or pictures of hyoid bones extracted from autopsies or anatomical collections [1, 11, 12, 14, 15, 22, 23]. Some of studies focused on two-dimensional computed tomography images from databases [7, 21] or X-ray films with various projections [17]. In this study, measurements of hyoid bone were performed on $\mathrm{CBCT}$ images which were made by two observers and intra-observer and inter-observer reliability was found to be high. This shows that the measurements made on the CBCT image of the hyoid bone are reproducible and reliable.

In this study, the mean age of the patients with fused hyoid bone was found to be higher than the unfused and partial fused hyoid bone. In previous studies $[8,18,21]$, it was reported that the ossification of the hyoid bone increased with age. This finding is

Table 2. Descriptive statistic results for age and measurements of all hyoid bones and comparison using $t$ tests

\begin{tabular}{|c|c|c|c|c|c|c|c|}
\hline & \multicolumn{2}{|c|}{ Male } & \multicolumn{2}{|c|}{ Female } & \multirow[t]{2}{*}{$P$ value } & \multicolumn{2}{|c|}{ Total } \\
\hline & Mean \pm SD & Range & Mean \pm SD & Range & & Mean \pm SD & Range \\
\hline Age [years] & $33.04 \pm 13.42$ & $15-55$ & $35.29 \pm 15.20$ & $14-55$ & 0.123 & $34.37 \pm 14.49$ & $14-55$ \\
\hline Hyd-W & $45.20 \pm 5.62$ & $35.40-58.00$ & $42.32 \pm 4.64$ & $28.60-54.50$ & $0.001^{*}$ & $43.50 \pm 5.15$ & $28.60-8.00$ \\
\hline$B-L$ & $23.75 \pm 2.49$ & $18.20-28.70$ & $20.39 \pm 2.12$ & $13.20-24.70$ & $<0.001^{*}$ & $21.77 \pm 2.81$ & $13.20-28.70$ \\
\hline Hyd-L & $37.74 \pm 4.00$ & $30.20-46.40$ & $32.28 \pm 3.01$ & $26.40-37.50$ & $<0.001^{*}$ & $34.52 \pm 4.36$ & $26.40-46.40$ \\
\hline RD-D & $3.38 \pm 0.73$ & $2.00-4.80$ & $3.11 \pm 0.55$ & $2.10-4.50$ & $0.017^{*}$ & $3.22 \pm 0.64$ & $2.00-4.80$ \\
\hline RP-W & $3.52 \pm 0.77$ & $2.10-4.90$ & $2.83 \pm 0.51$ & $2.00-4.10$ & $<0.001^{*}$ & $3.11 \pm 0.72$ & $2.00-4.90$ \\
\hline LD-D & $3.32 \pm 0.83$ & $2.00-5.00$ & $3.22 \pm 0.71$ & $2.00-5.20$ & 0.437 & $3.26 \pm 0.76$ & $2.00-5.20$ \\
\hline LP-W & $3.42 \pm 0.79$ & $2.00-5.10$ & $2.94 \pm 0.51$ & $1.80-4.10$ & $<0.001^{*}$ & $3.13 \pm 0.68$ & $1.80-5.10$ \\
\hline Stature & $86.30 \pm 7.38$ & 73.00-103.00 & $76.73 \pm 6.84$ & $60.40-90.40$ & $<0.001^{*}$ & $80.65 \pm 8.48$ & $60.40-103.00$ \\
\hline
\end{tabular}

SD — standard deviation; Hyd-W — hyoid width; B-L — body length; Hyd-L — hyoid length; RD-D — diameter of the right distal end; RP-W — width of the right proximal end; LD-D — diameter of the left distal end; LP-W — width of the left proximal end 
Table 3. Descriptive statistic results for the measurements of hyoid bones according to fusion types

\begin{tabular}{|c|c|c|c|c|c|c|c|}
\hline & \multirow[t]{2}{*}{ Sex } & \multicolumn{2}{|c|}{ Unfused hyoid } & \multicolumn{2}{|c|}{ Partially fused hyoid } & \multicolumn{2}{|c|}{ Fused hyoid } \\
\hline & & Mean & SD & Mean & SD & Mean & SD \\
\hline Age (years) & Total & 35.96 & 14.65 & 33.7 & 15.17 & 39.75 & 16.01 \\
\hline Hyd-W & $\begin{array}{l}\text { Male } \\
\text { Female } \\
\text { Total }\end{array}$ & $\begin{array}{l}46.86 \\
39.54 \\
42.59\end{array}$ & $\begin{array}{l}3.05 \\
5.45 \\
5.83\end{array}$ & $\begin{array}{l}44.93 \\
42.99 \\
43.76\end{array}$ & $\begin{array}{l}6.46 \\
4.17 \\
5.25\end{array}$ & $\begin{array}{l}44.13 \\
42.33 \\
43.23\end{array}$ & $\begin{array}{l}1.50 \\
2.05 \\
1.96\end{array}$ \\
\hline$B-L$ & $\begin{array}{l}\text { Male } \\
\text { Female } \\
\text { Total }\end{array}$ & $\begin{array}{l}22.82 \\
17.71 \\
19.84\end{array}$ & $\begin{array}{l}1.46 \\
2.10 \\
3.15\end{array}$ & $\begin{array}{l}24.34 \\
20.97 \\
22.30\end{array}$ & $\begin{array}{l}2.46 \\
1.69 \\
2.61\end{array}$ & $\begin{array}{l}21.60 \\
21.06 \\
21.33\end{array}$ & $\begin{array}{l}2.63 \\
0.90 \\
1.89\end{array}$ \\
\hline Hyd-L & $\begin{array}{l}\text { Male } \\
\text { Female } \\
\text { Total }\end{array}$ & $\begin{array}{l}37.38 \\
29.97 \\
33.05\end{array}$ & $\begin{array}{l}2.23 \\
2.32 \\
4.35\end{array}$ & $\begin{array}{l}38.28 \\
32.94 \\
35.06\end{array}$ & $\begin{array}{l}4.48 \\
2.97 \\
4.47\end{array}$ & $\begin{array}{l}34.93 \\
31.33 \\
33.13\end{array}$ & $\begin{array}{l}0.63 \\
2.06 \\
2.37\end{array}$ \\
\hline RD-D & $\begin{array}{l}\text { Male } \\
\text { Female } \\
\text { Total }\end{array}$ & $\begin{array}{l}3.26 \\
2.92 \\
3.06\end{array}$ & $\begin{array}{c}0.50 \\
0.47 \\
.50\end{array}$ & $\begin{array}{l}3.42 \\
3.17 \\
3.27\end{array}$ & $\begin{array}{l}0.82 \\
0.56 \\
0.69\end{array}$ & $\begin{array}{l}3.30 \\
2.96 \\
3.13\end{array}$ & $\begin{array}{l}0.23 \\
0.50 \\
0.41\end{array}$ \\
\hline RP-W & $\begin{array}{l}\text { Male } \\
\text { Female } \\
\text { Total }\end{array}$ & $\begin{array}{l}3.18 \\
2.47 \\
2.76\end{array}$ & $\begin{array}{c}0.61 \\
0.34 \\
.58\end{array}$ & $\begin{array}{l}3.63 \\
2.92 \\
3.20\end{array}$ & $\begin{array}{l}0.78 \\
0.53 \\
0.72\end{array}$ & $\begin{array}{l}3.43 \\
2.83 \\
3.13\end{array}$ & $\begin{array}{l}0.91 \\
0.36 \\
0.73\end{array}$ \\
\hline LD-D & $\begin{array}{l}\text { Male } \\
\text { Female } \\
\text { Total }\end{array}$ & $\begin{array}{l}3.82 \\
2.51 \\
3.05\end{array}$ & $\begin{array}{l}0.91 \\
0.34 \\
0.91\end{array}$ & $\begin{array}{l}3.24 \\
3.36 \\
3.31\end{array}$ & $\begin{array}{l}0.80 \\
0.64 \\
0.71\end{array}$ & $\begin{array}{l}3.03 \\
3.46 \\
3.25\end{array}$ & $\begin{array}{l}0.59 \\
1.03 \\
0.83\end{array}$ \\
\hline LP-W & $\begin{array}{l}\text { Male } \\
\text { Female } \\
\text { Total }\end{array}$ & $\begin{array}{l}3.48 \\
2.65 \\
3.00\end{array}$ & $\begin{array}{c}0.29 \\
0.13 \\
.46\end{array}$ & $\begin{array}{l}3.57 \\
2.93 \\
3.18\end{array}$ & $\begin{array}{l}0.79 \\
0.51 \\
0.71\end{array}$ & $\begin{array}{c}2.36 \\
3.7 \\
3.05\end{array}$ & $\begin{array}{l}0.49 \\
0.22 \\
0.80\end{array}$ \\
\hline Stature & $\begin{array}{l}\text { Male } \\
\text { Female } \\
\text { Total }\end{array}$ & $\begin{array}{l}82.38 \\
72.78 \\
76.78\end{array}$ & $\begin{array}{l}6.32 \\
8.99 \\
9.20\end{array}$ & $\begin{array}{l}88.10 \\
77.77 \\
81.86\end{array}$ & $\begin{array}{l}7.49 \\
6.21 \\
8.41\end{array}$ & $\begin{array}{l}81.50 \\
75.90 \\
78.70\end{array}$ & $\begin{array}{l}2.72 \\
3.74 \\
4.27\end{array}$ \\
\hline
\end{tabular}

SD — standard deviation; Hyd-W — hyoid width; B-L — body length; Hyd-L — hyoid length; RD-D — diameter of the right distal end; RP-W — width of the right proximal end; LD-D — diameter of the left distal end; LP-W — width of the left proximal end

Table 4. Sexual dimorphisms in the population

\begin{tabular}{|c|c|c|c|c|c|c|c|c|c|c|c|c|}
\hline & \multicolumn{4}{|c|}{ Un-fused hyoids } & \multicolumn{4}{|c|}{ Partially fused hyoids } & \multicolumn{4}{|c|}{ Fused hyoids } \\
\hline & $\begin{array}{c}\text { MD } \\
{[\mathrm{mm}]}\end{array}$ & t-value & DF & p-value & $\begin{array}{c}\text { MD } \\
{[\mathrm{mm}]}\end{array}$ & t-value & DF & p-value & $\begin{array}{c}\text { MD } \\
{[\mathrm{mm}]}\end{array}$ & t-value & DF & p-value \\
\hline Hyd-W & 7.13 & 3.82 & 22 & $0.001^{*}$ & 1.93 & 1.78 & 94 & 0.078 & 1.80 & 1.72 & 10 & 0.115 \\
\hline B-L & 5.10 & 6.60 & 22 & $<0.001^{*}$ & 3.37 & 7.94 & 94 & $<0.001^{*}$ & 0.53 & 0.46 & 10 & 0.649 \\
\hline Hyd-L & 7.40 & 7.81 & 22 & $<0.001^{*}$ & 5.33 & 7.01 & 94 & $<0.001^{*}$ & 3.60 & 4.08 & 10 & $0.002^{*}$ \\
\hline RD-D & 0.33 & 1.64 & 22 & 0.114 & 0.25 & 1.78 & 94 & 0.078 & 0.33 & 1.45 & 10 & 0.176 \\
\hline RP-W & 0.70 & 3.61 & 22 & $0.002^{*}$ & 0.71 & 5.29 & 94 & $<0.001^{*}$ & 0.60 & 1.49 & 10 & 0.167 \\
\hline LD-D & 1.30 & 4.90 & 22 & $<0.001^{*}$ & -0.12 & -0.82 & 94 & 0.410 & -0.43 & -0.89 & 10 & 0.394 \\
\hline LP-W & 0.82 & 9.27 & 22 & $<0.001^{*}$ & 0.64 & 4.80 & 94 & $<0.001^{*}$ & -1.36 & -6.18 & 10 & $<0.001 *$ \\
\hline Stature & 9.59 & 2.89 & 22 & $0.008^{*}$ & 10.32 & 7.33 & 94 & $<0.001^{*}$ & 5.60 & 2.96 & 10 & $0.014^{*}$ \\
\hline
\end{tabular}

${ }^{*}$ Statistical significance level is $p<0.05 ; \mathrm{MD}$ — mean difference; DF — degrees of freedom; Hyd-W — hyoid width; B-L — body length; Hyd-L — hyoid length; RD-D — diameter of the right distal end; RP-W — width of the right proximal end; LD-D — diameter of the left distal end; LP-W - width of the left proximal end

consistent with the results of this study. Consistent with the results of previous studies $[5,14,19,21,23]$, the mean values of all measurements of hyoid bone in all fusion types except LD-D were higher in males than females. Similarly, Logar et al. [14] reported that there was no significant difference between the sexes on the average of the maximum height of the upper end of the both left and right cornua. 
Table 5. Male and female and fusion types with regard to age groups

\begin{tabular}{|c|c|c|c|c|c|}
\hline \multirow[t]{2}{*}{ Age groups } & \multirow[t]{2}{*}{ Sex } & \multicolumn{3}{|c|}{ Fusion types } & \multirow[t]{2}{*}{ P-value } \\
\hline & & 1 (non-fusion) & 2 (partial fusion) & 3 (fusion) & \\
\hline$<20$ years & $\begin{array}{l}\text { Male } \\
\text { Female } \\
\text { Total }\end{array}$ & $\begin{array}{c}24(85.0 \%) \\
22(55.0 \%) \\
59(71 \%)\end{array}$ & $\begin{array}{c}6(15.0 \%) \\
14(35.0 \%) \\
20(25.0 \%)\end{array}$ & $\begin{array}{c}- \\
4(10.0 \%) \\
4(5.0 \%)\end{array}$ & 0.150 \\
\hline Young adult ( $20-30$ years) & $\begin{array}{l}\text { Male } \\
\text { Female } \\
\text { Total }\end{array}$ & $\begin{array}{c}24(75 \%) \\
48(92.4 \%) \\
72(85.7 \%)\end{array}$ & $\begin{array}{l}2(6.2 \%) \\
2(3.8 \%) \\
4(4.8 \%)\end{array}$ & $\begin{array}{c}6(18.8 \%) \\
2(3.8 \%) \\
8(9.5 \%)\end{array}$ & $0.025^{*}$ \\
\hline Adult ( $31-55$ years) & $\begin{array}{l}\text { Male } \\
\text { Female } \\
\text { Total }\end{array}$ & $\begin{array}{l}26(72.2 \%) \\
58(90.6 \%) \\
84(84.0 \%)\end{array}$ & $\begin{array}{c}4(11.1 \%) \\
- \\
4(4.0 \%)\end{array}$ & $\begin{array}{c}6(16.7 \%) \\
6(9.4 \%) \\
12(12.0 \%)\end{array}$ & 0.068 \\
\hline
\end{tabular}

${ }^{*}$ Statistical significance level is $p<0.05$

Table 6. Discriminant functions for all hyoid bones in the population

\begin{tabular}{|c|c|c|c|c|c|c|c|c|c|}
\hline & \multicolumn{2}{|c|}{ Group centroid } & \multirow{2}{*}{$\begin{array}{c}\text { Sectioning } \\
\text { point }\end{array}$} & \multirow{2}{*}{$\begin{array}{l}\text { Wilks' } \\
\text { lambda }\end{array}$} & \multirow[t]{2}{*}{ Eigenvalue } & \multirow{2}{*}{$\begin{array}{l}\text { Canonical } \\
\text { correlation }\end{array}$} & \multicolumn{3}{|c|}{ Correct prediction rates (\%) } \\
\hline & Male & Female & & & & & Male & Female & Overall \\
\hline Hyd-W & 0.342 & -0.237 & 0.052 & 0.924 & 0.082 & 0.275 & 29.6 & 84.6 & 57.1 \\
\hline$B-L$ & 0.871 & -0.603 & 0.134 & 0.652 & 0.533 & 0.590 & 70.4 & 92.3 & 81.35 \\
\hline Hyd-L & 0.933 & -0.646 & 0.143 & 0.620 & 0.612 & 0.616 & 59.3 & 87.2 & 73.25 \\
\hline RD-D & 0.252 & -0.174 & 0.036 & 0.957 & 0.045 & 0.207 & 22.2 & 89.7 & 55.95 \\
\hline RP-W & 0.643 & -0.445 & 0.099 & 0.775 & 0.291 & 0.475 & 51.9 & 87.2 & 69.55 \\
\hline LP-W & 0.441 & -0.305 & 0.068 & 0.880 & 0.136 & 0.347 & 40.7 & 79.5 & 60.1 \\
\hline Stature & 0.800 & -0.554 & 0.123 & 0.690 & 0.450 & 0.557 & 70.4 & 82.1 & 76.25 \\
\hline
\end{tabular}

Since the left distal diameter is not statistically significant, it is not included in the model. Hyd-W — hyoid width; B-L — body length; Hyd-L — hyoid length; RD-D — diameter of the right distal end; RP-W - width of the right proximal end; LP-W — width of the left proximal end

All measurements except RD-D of unfused hyoid bone measurements showed sexual dimorphism in present study. B-L, Hyd-L, RP-W, LP-W and stature measurements of partially fused hyoid bone and $\mathrm{Hyd}-\mathrm{L}$, LP-W and stature measurements of fused hyoid bone showed sexual dimorphism. Although Reesink et al. [17] did not find any significant sex difference in the length of the cornu major, in our study Hyd-W of unfused hyoid bone measurements showed sexual dimorphism consisted with D'Anastasio et al. [2] and Shimizu et al. [18]. In the studies of Leksan et al. [13] and Shimizu et al. [18] B-L in males was significantly longer than that in females in all age groups which is concordant with our unfused and partially fused hyoid bone measurements. This means that discriminant function equations obtained from parameters showing sexual dimorphism can be used for sex determination.

In this study, B-L and Hyd-L showed a high prediction rate. Similarly, in the study of Torimitsu et al. [21] and Urbanová et al. [23], Hyd-L and B-L showed the highest level of sexual dimorphism. In addition, Pollard et al. [16] and Mukhopadhyay [15] previously reported that the female hyoid bones were generally large; therefore, the total anteroposterior length was reported to be more useful in predicting sex than Hyd-W. In this study, B-L achieved a successful sexual prediction rate of $>80 \%$. Considering these results, it can be said that sex can be predicted even when there is no bone other than hyoid bone.

With the introduction of CBCT in dentistry, there has been an improvement in the ability to analyse bone structures in three-dimensional imaging [3]. Multiplanar images obtained from all planes were used to evaluate bone morphology. One-to-one measurements of bone structures can be made on sections formed in desired thickness and desired plane. Today, CBCT is an easily accessible and easily acquired imaging system with a relatively low radiation dose. It can be obtained from individuals so that measurements in the images can be used to estimate age and gender in forensic cases [4]. 


\section{CONCLUSIONS}

In this study, hyoid bone showed important morphologic changes and differences according to age and sex which can be useful in forensic science for age and sex estimation with high predictive rates. Imaging hyoid bone with CBCT is simple, easily applicable and very reproducible methodology. So, in forensic medicine, accurate measurements and evaluation can be performed by CBCT in living individuals with lower radiation dose. To support the results of the study, new studies are needed in which the distribution of sex is equal and the age groups are similar and with volume measurements.

\section{Conflict of interest: None declared}

\section{REFERENCES}

1. Balseven-Odabasi A, Yalcinozan E, Keten A, et al. Age and sex estimation by metric measurements and fusion of hyoid bone in a Turkish population. J Forensic Leg Med. 2013; 20(5): 496-501, doi: 10.1016/j.jflm.2013.03.022, indexed in Pubmed: 23756521.

2. D'Anastasio R, Viciano J, Di Nicola M, et al. Estimation of sex from the hyoid body in skeletal individuals from archeological sites. Homo. 2014; 65(4): 311-321, doi: 10.1016/j. jchb.2014.01.002, indexed in Pubmed: 24767538.

3. da Costa ED, Roque-Torres GD, Brasil DM, et al. Correlation between the position of hyoid bone and subregions of the pharyngeal airway space in lateral cephalometry and cone beam computed tomography. Angle Orthod. 2017; 87(5): 688-695, doi: 10.2319/022217-133.1, indexed in Pubmed: 28686091.

4. El-Shal O, Shaaban A. Evaluation of different mandibular measurements by cone beam computed tomography as a forensic age \& gender determination tools. Al-Azhar D J. 2019; 6(4): 445-452, doi: 10.21608/adjg.2019.7749.1098.

5. Fakhry N, Puymerail L, Michel J, et al. Analysis of hyoid bone using 3D geometric morphometrics: an anatomical study and discussion of potential clinical implications. Dysphagia. 2013; 28(3): 435-445, doi: 10.1007/s00455013-9457-x, indexed in Pubmed: 23456326.

6. Feng X, Todd T, Hu Y, et al. Age-related changes of hyoid bone position in healthy older adults with aspiration. Laryngoscope. 2014; 124(6): E231-E236, doi: 10.1002/ lary.24453, indexed in Pubmed: 24227680.

7. Fisher $E$, Austin $D$, Werner HM, et al. Hyoid bone fusion and bone density across the lifespan: prediction of age and sex. Forensic Sci Med Pathol. 2016; 12(2): 146-157, doi: 10.1007/ s12024-016-9769-x, indexed in Pubmed: 27114259.

8. Gupta A, Kohli A, Aggarwal NK, et al. Study of age of fusion of hyoid bone. Leg Med (Tokyo). 2008; 10(5): 253-256, doi: 10.1016/j.legalmed.2008.03.002, indexed in Pubmed: 18442944.

9. Ha JG, Min HJ, Ahn SH, et al. The dimension of hyoid bone is independently associated with the severity of obstructive sleep apnea. PLoS One. 2013; 8(12): e81590, doi: 10.1371/ journal.pone.0081590, indexed in Pubmed: 24312562.

10. Kanetaka H, Shimizu Y, Kano M, et al. Synostosis of the joint between the body and greater cornu of the human hyoid bone. Clin Anat. 2011; 24(7): 837-842, doi: 10.1002/ ca.21183, indexed in Pubmed: 21538567.
11. Kim DI, Lee UY, Park DK, et al. Morphometrics of the hyoid bone for human sex determination from digital photographs. J Forensic Sci. 2006; 51(5): 979-984, doi: 10.1111/j.1556-4029.2006.00223.x, indexed in Pubmed: 17018072 .

12. Kindschuh SC, Dupras TL, Cowgill LW. Determination of sex from the hyoid bone. Am J Phys Anthropol. 2010; 143(2): 279-284, doi: 10.1002/ajpa.21315, indexed in Pubmed: 20853481.

13. Leksan I, Marcikić M, Nikolić V, et al. Morphological classification and sexual dimorphism of hyoid bone: new approach. Coll Antropol. 2005; 29(1): 237-242, indexed in Pubmed: 16117329.

14. Logar CJ, Peckmann TR, Meek S, et al. Determination of sex from the hyoid bone in a contemporary White population. J Forensic Leg Med. 2016; 39: 34-41, doi: 10.1016/j. jflm.2016.01.004, indexed in Pubmed: 26817970.

15. Mukhopadhyay PP. Morphometric features and sexual dimorphism of adult hyoid bone: a population specific study with forensic implications. J Forensic Leg Med. 2010; 17(6): 321-324, doi: 10.1016/j.jflm.2010.04.014, indexed in Pubmed: 20650421.

16. Pollard J, Piercecchi-Marti MD, Thollon L, et al. Mechanisms of hyoid bone fracture after modelling: evaluation of anthropological criteria defining two relevant models. Forensic Sci Int. 2011; 212(1-3): 274.e1-274.e5, doi: 10.1016/j.forsciint.2011.06.020, indexed in Pubmed: 21764532.

17. Reesink EM, Immerseel AV, Brand $R$, et al. Sexual dimorphism of the hyoid bone? Int J Osteoarchaeol. 1999; 9(5): 357-360, doi: 10.1002/(sici)10991212(199909/10)9:5<357::aid-oa494>3.0.co;2-j.

18. Shimizu Y, Kanetaka H, Kim YH, et al. Age-related morphological changes in the human hyoid bone. Cells Tissues Organs. 2005; 180(3): 185-192, doi: 10.1159/000088247, indexed in Pubmed: 16260865.

19. Soltani S, Aghakhani K, Fallah F. Sex prediction potential of hyoid metric measurements in Iranian adults. Leg Med (Tokyo). 2017; 25: 6-10, doi: 10.1016/j.legalmed.2016.12.010, indexed in Pubmed: 28457512.

20. Teke HY, Duran S, Canturk N, et al. Determination of gender by measuring the size of the maxillary sinuses in computerized tomography scans. Surg Radiol Anat. 2007; 29(1): 9-13, doi: 10.1007/s00276-006-0157-1, indexed in Pubmed: 17171233.

21. Torimitsu S, Makino $Y$, Saitoh $H$, et al. Determination of sex on the basis of hyoid bone measurements in a Japanese population using multidetector computed tomography. Int J Legal Med. 2018; 132(3): 907-914, doi: 10.1007/s00414-017-1728-x, indexed in Pubmed: 29098386.

22. Urbanová $P$, Hejna $P$, Zátopková $L$, et al. The morphology of human hyoid bone in relation to sex, age and body proportions. Homo. 2013; 64(3): 190-204, doi: 10.1016/j. jchb.2013.03.005, indexed in Pubmed: 23648280.

23. Urbanová $P$, Hejna $P$, Zátopková $L$, et al. What is the appropriate approach in sex determination of hyoid bones? J Forensic Leg Med. 2013; 20(8): 996-1003, doi: 10.1016/j. jflm.2013.08.010, indexed in Pubmed: 24237807.

24. Ward RE, Jamison PL. Measurement precision and reliability in craniofacial anthropometry: implications and suggestions for clinical applications. J Craniofac Genet Dev Biol. 1991; 11(3): 156-164, indexed in Pubmed: 1761648.

25. Weinberg SM, Scott NM, Neiswanger K, et al. Intraobserver error associated with measurements of the hand. Am J Hum Biol. 2005; 17(3): 368-371, doi: 10.1002/ ajhb.20129, indexed in Pubmed: 15849702. 